\title{
Adaptation of flower and fruit colours to multiple, distinct
}

\section{mutualists}

\author{
Julien P. Renoult ${ }^{1}$, Alfredo Valido ${ }^{2}$, Pedro Jordano ${ }^{2}$ and H. Martin Schaefer ${ }^{1}$ \\ ${ }^{1}$ Department of Evolutionary Biology and Animal Ecology, Faculty of Biology, University of Freiburg, Hauptstrasse 1, 79104 Freiburg, Germany; ${ }^{2}$ Integrative Ecology Group, Estación \\ Biológica de Doñana (EBD-CSIC), C/Américo Vespucio s/n, Isla de La Cartuja, Sevilla E-41092, Spain
}

Author for correspondence:

Julien P. Renoult

Tel: + 497612032531

Email: jurenoult@gmail.com

Received: 20 March 2013

Accepted: 29 August 2013

New Phytologist (2014) 201: 678-686

doi: $10.1111 / \mathrm{nph} .12539$

Key words: colour, community, flower, fruit, mutualism, pollination, seed dispersal, stimulation landscape.

\section{Summary}

- Communication in plant-animal mutualisms frequently involves multiple perceivers. A fundamental uncertainty is whether and how species adapt to communicate with groups of mutualists having distinct sensory abilities.

- We quantified the colour conspicuousness of flowers and fruits originating from one European and two South American plant communities, using visual models of pollinators (bee and fly) and seed dispersers (bird, primate and marten).

- We show that flowers are more conspicuous than fruits to pollinators, and the reverse to seed dispersers. In addition, flowers are more conspicuous to pollinators than to seed dispersers and the reverse for fruits. Thus, despite marked differences in the visual systems of mutualists, flower and fruit colours have evolved to attract multiple, distinct mutualists but not unintended perceivers. We show that this adaptation is facilitated by a limited correlation between flower and fruit colours, and by the fact that colour signals as coded at the photoreceptor level are more similar within than between functional groups (pollinators and seed dispersers).

- Overall, these results provide the first quantitative demonstration that flower and fruit colours are adaptations allowing plants to communicate simultaneously with distinct groups of mutualists.

\section{Introduction}

Pollination and seed dispersal mutualisms form complex interaction networks potentially involving dozens of species (Waser et al., 1996; Bascompte \& Jordano, 2007). In such mutualistic networks, communicative traits such as colour and odour signals in flowers and fruits generally are subject to multiple selective pressures (Schaefer \& Ruxton, 2011). Two main factors are then expected to shape the evolution of plant signals: the convergence (versus conflict) of selective pressures, which is mainly determined by the degree of similarity in the sensory perception of multiple perceivers (Campell \& Aldridge, 2006; Lomáscolo \& Schaefer, 2010; Lomáscolo et al., 2010); and the extent to which intrinsic mechanisms, such as the physicochemical nature of traits, pleiotropy and genetic correlations, and selection by other players constrain evolvability (Hansen, 2003). These two factors have rarely been considered together; thus it is still an open question whether and how plant signals are adapted to communicate to multiple, distinct mutualists.

Different properties of plant signals can be selected by pollinators and seed dispersers. Colour signals, for example, can be selected for the biochemical (e.g. antioxidants; Schaefer et al., 2008) or visual properties of pigments (Schmidt etal., 2004). Conspicuousness is an important visual property of flower and fruit colours, as it can be an adaptation improving plant dispersal. For instance, the intensity of the colour contrast between the background and artificial flowers and fruits (our definition of conspicuousness hereafter) is negatively correlated with search time in bumblebees (Spaethe et al., 2001) and positively correlated with visitation rate in seed-dispersing birds (Cazetta et al., 2009). Yet, because these results stem from experiments on either a single species or a single type of perceiver, a major unknown in plant-animal communication is whether flower and fruit colours can be simultaneously conspicuous to several mutualists.

Theoretically, several factors should limit simultaneous adaptation of flower and fruit colours to the visual system of several mutualist agents. First, pollen and seeds are most frequently dispersed by animals with distinct and marked differences in their visual system. For example, some pollinating flies are probably tetrachromatic (i.e. use four types of photoreceptor for colour vision; for details, see Supporting Information Methods S1), whereas bees are trichromatic (Briscoe \& Chittka, 2001). Similarly, seed-dispersing birds are tetrachromatic, whereas primates are either dichromatic or trichromatic and other seed-dispersing mammals such as foxes and martens are dichromatic (Osorio \& Vorobyev, 2005). If differences in the number of photoreceptor types translate into perceptual differences, colour signals would have to simultaneously adapt to distinct visual systems. Secondly, 
increasing conspicuousness to several mutualists simultaneously increases conspicuousness to nectar/pollen robbers and pulp/seed predators, that is, to antagonists already known to perceive and select colour signals. Indeed, physicochemical mechanisms underlying colour stimuli cause them to be characterized by continuous, smoothly shaped reflectance spectra (Jaaskelainen et al., 1990). In contrast to other stimuli such as odours, colour stimuli cannot exhibit peaks of stimulation that are sharply tuned to specific receptor sensitivities. Rather, flower and fruit colours have necessarily broad reflectance spectra, possibly also in order to simultaneously stimulate different visual systems. However, given that visual systems processing colour stimuli invariably consist of a limited number of different types of photoreceptor with broad and overlapping sensitivities (van Hateren, 1993), broadband reflectance spectra stimulating the visual system of intended perceivers would also stimulate that of unintended perceivers. Lastly, the pleiotropic nature of genes coding for colour traits and correlations between genes involved in flower and fruit colouration could further limit separate adaptation to pollinators and seed dispersers if these have differing colour perception (Strauss \& Whittall, 2006).

We here assess whether adaptations to distinct mutualists occur in flower and fruit colouration. Using psychophysical models of colour vision, we estimated the conspicuousness of flower and fruit colours to pollinators (bee and fly) and to seed dispersers (bird, primate and marten). Adaptation is expected to occur if flowers are more conspicuous to pollinators than fruits are, and likewise for fruits and seed dispersers relative to flowers. This condition may be facilitated or hampered depending on pleiotropic factors and genetic correlations between flower and fruit colouration. We thus analysed the influence of correlation between flower and fruit colouration on conspicuousness at different time-scales. In addition, selection by mutualists for increased conspicuousness should generate differential conspicuousness to mutualists and to nonmutualists as a signature of adaptation, provided that these two groups have different perception of colours. We thus tested whether conspicuousness is higher to mutualists than to nonmutualists, and we investigated the degree of perceptual similarities among mutualists and between mutualists and nonmutualists. More precisely, we used a modelling approach to evaluate how differences in the number and sensitivity of photoreceptor types translate into photoreceptor signals. The finding that flowers are both more conspicuous to pollinators than fruits are and more conspicuous to pollinators than to seed dispersers (and vice versa for fruits) would represent the first quantitative demonstration that flower and fruit colours are in general adapted to the eyes of distinct types of perceiver within diversified mutualisms.

\section{Materials and Methods}

\section{Studied plants and animals}

The data on flower and fruit colouration come from one European and two South American plant communities. The colouration of both flowers and fleshy fruits of 102 European species belonging to 28 plant families was measured between 2007 and 2012. Most of these species were collected in Mediterranean scrublands in southern Spain (see Valido et al., 2011) and a few additional species were collected in the botanical garden of the University of Freiburg, Germany. For the few flowers that appeared multicoloured to human eyes, we considered the dominant colour only. In southern Spain, bees and flies are the two main groups of pollinator (Herrera, 1988), whereas birds and mammals such as foxes and martens are the main seed dispersers for fleshy-fruited plants (Herrera, 1995). Furthermore, Barbary macaques (Macaca sylvanus) were relatively common in Spain until the last glaciation (<0.1 Ma; Valverde, 1967). Based on the diet of extant individuals from Morocco (El Alami \& Chait, 2012), we further treated the Barbary macaque as a likely seed disperser of the Spanish plant community in the past.

In South America the colouration of fruits from 111 species (45 families) was measured in 2006 in Ilha do Cardoso, southern Brazil. In this subtropical island, birds are the main seed dispersers, and primates contribute to the seed dispersal of some of the studied plants (Cazetta et al., 2012). In 2009 we measured floral colouration in 67 species (23 families) in the coastal community of Los Molles, northern Chile, where bees and flies are the main pollinators and only one hummingbird species occurs (R. Medel et al., unpublished data). For 10 species, flowers exhibited more than one colour in approximately equal proportion. We measured these colours separately. Colour data were not available for flowers in Ilha do Cardoso and for fruits in Los Molles.

\section{Colour measurements}

We measured the reflectance spectra of flowers, mature fleshy fruits and leaves gently detached from the plants using an Ocean Optic USB2000 (Ocean Optic, Dunedin, FL, USA) or an Avaspec 2048 (Avantes, Apeldoorn, the Netherlands) spectrometer following the procedure described in Schaefer et al. (2007). For each plant structure of each species, we averaged replicated measurements from five to 20 items collected from different individuals. We defined leaf colouration as the background against which flowers and fruits are perceived by mutualists. Within a given community, we then used the same, averaged leaf colouration for all species because fruit colours are not adapted to be conspicuous against their own, species-specific foliage (Schaefer et al., 2007), and because the variation among leaf colours is very limited compared with the variation among fruit or flower colours when viewed by pollen and seed dispersers (Chittka, 1997; Regan et al., 2001).

\section{Modelling conspicuousness}

Colour conspicuousness was calculated as the distance between the signalling stimulus (flower or fruit) and the background (leaf) locations in a colour space, which is a graphical representation of how colour stimuli appear to the eye of a given perceiver. We estimated the conspicuousness of Spanish flowers and fruits in six different colour spaces describing the visual systems of honeybees, hoverflies, macaques, martens and birds (two types of visual 
system; for details, see Methods S1). The conspicuousness of Brazilian fruits was measured within the colour space of birds (two types) and New World primates. Because most New World primates exhibit polymorphism at an X-chromosome opsin gene, six visual systems (either dichromatic or trichromatic) can theoretically be found within the same population (Jacobs, 2008). In addition, photoreceptor sensitivities differ between Callitrichidae (e.g. marmosets and tamarins) and Cebidae (Cebus and squirrel monkeys) families, leading to 12 possible visual systems in polymorphic New World primates (Jacobs, 2008). We included nine of these 12 systems in our analyses because three of them were almost redundant (Methods S1). The conspicuousness of Chilean flowers was modelled to the eyes of bees and hoverflies using the same data as for the Spanish flowers. Overall, we investigated the colour conspicuousness to five groups of perceivers (bees, flies, martens, primates and birds) characterized by 15 distinct visual systems.

We used two approaches to model colour spaces and to calculate conspicuousness. First, we applied the classical receptor noise limited (RNL) model of colour vision (Vorobyev \& Osorio, 1998; Methods S1). The RNL model was originally developed to evaluate small perceptual differences in the colour space, that is, differences close to the detection threshold, but the model has also been successfully applied to estimate larger differences (e.g. in honeybees: Hempel et al., 2001; in birds: Stobbe \& Schaefer, 2008; Cazetta et al., 2009). In the RNL model, one unit of perceptual distance corresponds to one just noticeable difference (JND). Previously, we argued that colour conspicuousness as measured by traditional psychophysical models of colour vision, such as the RNL model, cannot be compared directly among species (for details, see Renoult etal., 2013). Thus, in a second approach we used the method of the stimulation landscape (Stimuland) that standardizes values of conspicuousness (Renoult et al., 2013). A stimulation landscape consists of a spectral space (the same for the 15 landscapes, i.e. one for each visual system), which is a six-dimensional space describing variation in reflectance spectra, plus one dimension (unique to each landscape) indicating the conspicuousness value for each spectrum (see Methods S1). The colour space used in the stimulation landscape was a chromaticity diagram extracted from the photoreceptor contrast space, which is the multidimensional space describing for each photoreceptor type the ratio between the quantum catch associated with the signalling stimulus and that associated with background stimulus (Kelber et al., 2003). Here, conspicuousness is evaluated as the Euclidean distance between the stimulus and the centre of the diagram. We then randomly resampled $10^{5}$ times each of the six variables of the spectral space to generate reference sets of reflectance spectra and conspicuousness values. Conspicuousness was eventually standardized (within the interval $[0 ; 1])$ using the cumulative distribution of reference conspicuousness values (Methods S1).

\section{Statistical analyses}

We studied the adaptation of flower and fruit colours to the eyes of their mutualistic agents using generalized linear mixed models implemented in the R package MCMCglmm (Hadfield, 2010; R Development Core Team, 2011). The three communities were analysed separately and in combination (pooling flowers from Spain and Chile, and fruits from Spain and Brazil, respectively). The response variable was the conspicuousness, expressed either in JNDs (RNL model) or in standardized units (Stimuland), of flower and fruit colours modelled according to the visual systems of the perceivers present in a given community. For the combined data set, we considered the visual systems of those animals that occurred in all three communities: bees, flies, birds and trichromatic primates. For the latter visual system, we analysed conspicuousness to macaques because their photoreceptor sensitivities are close to that of Cebidae from the New World (for details, see Methods S1). Explanatory variables included the number of photoreceptor types (di-, tri- or tetrachromatic), the dispersal service provided by the perceiver (pollinator or seed disperser) and, for the Spanish data set that included both flower and fruit spectra, the reproductive structure (flower or fruit) and interactions between plant structure and each of the other two fixed factors. We added a random effect term to account for the nonindependence between values of conspicuousness calculated with a given visual system. For the Spanish data, we further compared this model with two other models coding either plant species or the full plant phylogeny (see Methods S2) in a second random effect nested within the perceiver group. By accounting for the nonindependence of colouration among plant structures within taxa, these two models allowed the investigation of the influence of pleiotropy or genetic correlations in flower and fruit colouration. We specified a gamma distribution of the response variable with identity link function for all models. Models were fitted with $3 \times 10^{6}$ iterations, discarding the first million and sampling every 200 iterations. We used flat uninformative priors with a uniform low degree of belief across all parameters. Models were compared based on the deviance information criterion (DIC; Hadfield, 2010).

In order to investigate how differences in the number and sensitivity of photoreceptor types translate into differences in photoreceptor signals, we assessed the differences in shape between the 15 standardized stimulation landscapes. This was achieved by calculating a canonical distance matrix between visual systems from the standardized conspicuousness corresponding to the $10^{5} \mathrm{col}-$ our spectra randomly sampled in the spectral space. This distance matrix was used to build a tree by hierarchical clustering with the average method using R ( $\mathrm{R}$ Development Core Team, 2011). The tree describes the relationships between visual systems based on their similarities in colour signals coded at the photoreceptor level.

\section{Results}

\section{Correlations between flower and fruit colours}

In the Spanish community, the models discounting the correlation between flower and fruit colouration within taxa had a markedly poorer fit $\left(\mathrm{DIC}_{\mathrm{RNL}}=7705\right.$; $\left.\mathrm{DIC}_{\text {stimuland }}=-884\right)$ than that of models accounting for such a correlation. Among the 
latter, the models coding plant species $\left(\mathrm{DIC}_{\mathrm{RNL}}=7626\right.$; $\left.\mathrm{DIC}_{\text {stimuland }}=-1098\right)$ was better than the model coding the full plant phylogeny $\left(\mathrm{DIC}_{\mathrm{RNL}}=7629\right.$; $\left.\mathrm{DIC}_{\text {stimuland }}=-1086\right)$. Fruit colouration and flower colouration within the same species are thus not independent, although the shared ancestry with more distant taxa (congeneric and confamilial species) does not affect the strength of this correlation for the species set studied. Only models coding for plant species are considered in the following analyses of the Spanish data.

\section{Comparison between flower and fruit conspicuousness}

Using either RNL models or stimulation landscapes, colour conspicuousness was significantly influenced by the interaction between disperser (pollinators or seed dispersers) and the reproductive structure of the plant (flower or fruit) in both the combined (e.g. $\beta_{\mathrm{RNL}}=1.01 ; P<0.001$; Table 1a) and the Spanish data sets (e.g. $\beta_{\mathrm{RNL}}=1.28 ; P<0.001$; Table $1 \mathrm{~b}$; no interaction term in Brazilian and Chilean data sets). Specifically, flowers were more conspicuous to pollinators than fruits were with specified factor contrasts (e.g. combined data set: $\beta_{\mathrm{RNL}}=1.13 ; P<0.001$; Fig. 1a-d), and fruits were more conspicuous to seed dispersers than flowers were (e.g. combined data set: $\beta_{\mathrm{RNL}}=-0.52$; $P<0.001)$.

Based on stimulation landscapes, in all analyses we further found that flowers were more conspicuous to pollen dispersers than to seed dispersers (e.g. with Chilean data: $\beta_{\text {stimuland }}=-0.59$; $P<0.001$; Table $1 \mathrm{~d}$ ), and the reverse for fruits (e.g. with Brazilian data: $\beta_{\text {stimuland }}=0.34 ; P=0.005$; Table 1c). This result did not hold for RNL models, except when birds were excluded (results not shown). However, given that comparing large perceptual distances measured with RNL models across species leads to unreliable results (Renoult et al., 2013), we propose that flower and fruit colours are more salient to their respective mutualists than they are to nonmutualists.

For a given plant structure there was no effect of the number of photoreceptor types on conspicuousness in any visual model or data set. This is attested by the lack of significance of the interaction term between photoreceptor number and plant structure in the overall and Spanish data sets (Table 1a,b), and of the simple effect term of photoreceptor number for the Chilean and Brazilian data (Table 1c,d). Thus, adaptations of flower and fruit colours appear independent of the number of photoreceptor types used for colour vision.

\section{Comparison between stimulation landscapes}

Comparing the standardized conspicuousness of simulated colour spectra revealed substantial variation in the shape of stimulation landscapes among perceivers that provide a similar service of dispersion. This is shown by the terminal branches on the tree of shape similarities, which are different from zero (Fig. 2). Shape similarities were not explained by the number of photoreceptor types used to process colour stimuli: for example, fly and bee stimulation landscapes are clustered with maximal bootstrap support. Rather, the clustering of fly and bee landscapes on the one hand, and of primates, birds and dichromatic mammals on the other hand indicates that dispersal service or the phylogeny of animals can determine similarities in stimulation landscapes.

\section{Discussion}

Most studies on colour signalling in plant dispersal mutualisms have focused on interactions between plants and a specific pollinator and seed disperser (Chittka \& Menzel, 1992; Lomáscolo \& Schaefer, 2010; Lomáscolo etal., 2010). These studies have

Table 1 Results of the generalized linear mixed-effect model with data from all flowers and fruits corresponding to 280 species (a), with Spanish flowers and fruits of 102 species (b), with Brazilian fruits of 111 species (c) and with Chilean flowers of 67 species (d)

\begin{tabular}{|c|c|c|c|c|c|}
\hline & Fixed factors & Post mean of $\beta$ & Lower 95\% & Upper 95\% & $\mathrm{pMCMC}$ \\
\hline \multirow[t]{6}{*}{ (a) } & Intercept & $1.72 / 1.76$ & $1.48 / 1.52$ & $2.07 / 2.01$ & $<0.001 /<0.001$ \\
\hline & Plant structure & $-0.26 /-0.51$ & $-0.39 /-0.64$ & $-0.12 /-0.37$ & $<0.001 /<0.001$ \\
\hline & No. photoreceptor types & $-0.15 / 0.09$ & $-13.18 /-0.38$ & $11.26 / 0.53$ & ns/ns \\
\hline & Dispersal service & $0.11 /-1.03$ & $-9.18 /-1.39$ & $9.30 /-0.65$ & $\mathrm{~ns} /<0.001$ \\
\hline & Structure $\times$ photoreceptor & $0.19 /-0.14$ & $-0.02 /-0.36$ & $0.41 / 0.06$ & ns/ns \\
\hline & Structure $\times$ service & $1.01 / 1.43$ & $0.79 / 1.20$ & $1.23 / 1.66$ & $<0.001 /<0.001$ \\
\hline \multirow[t]{6}{*}{ (b) } & Intercept & $1.92 / 1.95$ & $1.56 / 1.70$ & $2.31 / 2.21$ & $<0.001 /<0.001$ \\
\hline & Plant structure & $-0.44 /-0.66$ & $-0.61 /-0.82$ & $-0.28 /-0.51$ & $<0.001 / 0.008$ \\
\hline & No. photoreceptor types & $-0.16 / 0.37$ & $-17.20 /-0.03$ & $15.30 / 1.04$ & ns/ns \\
\hline & Dispersal service & $-0.08 /-1.24$ & $-6.69 /-1.68$ & $6.67 /-0.86$ & $\mathrm{~ns} /<0.001$ \\
\hline & Structure $\times$ photoreceptor & $-0.22 /-0.32$ & $-0.65 /-0.68$ & $0.20 / 0.04$ & $\mathrm{~ns} / \mathrm{ns}$ \\
\hline & Structure $\times$ service & $1.28 / 1.67$ & $0.99 / 1.41$ & $1.56 / 1.94$ & $<0.001 /<0.001$ \\
\hline \multirow[t]{3}{*}{ (c) } & Intercept & $-1.92 / 0.97$ & $-4.12 / 0.82$ & $0.43 / 1.10$ & $0.08 /<0.001$ \\
\hline & No. photoreceptor types & $-0.48 / 0.23$ & $-4.18 / 0.02$ & $3.38 / 0.48$ & $\mathrm{~ns} / \mathrm{ns}$ \\
\hline & Dispersal service & $0.88 / 0.34$ & $-2.99 / 0.10$ & $4.59 / 0.55$ & ns/0.005 \\
\hline \multirow[t]{3}{*}{ (d) } & Intercept & $-1.84 / 1.12$ & $-3.71 / 0.94$ & $0.09 / 1.26$ & $0.064 /<0.001$ \\
\hline & No. photoreceptor types & $-0.63 / 0.17$ & $-3.73 /-0.02$ & $2.34 / 0.38$ & $\mathrm{~ns} / \mathrm{ns}$ \\
\hline & Dispersal service & $0.01 /-0.59$ & $-3.21 /-0.85$ & $3.02 /-0.34$ & $\mathrm{~ns} /<0.001$ \\
\hline
\end{tabular}

Each cell indicates results with the receptor noise limited (RNL) model (left) and with the stimulation landscape (right). The random part includes the visual system (in all models) and species (with Spanish data). Results are provided with default factor contrasts. ns, not significant. pMCMC, Bayesian $P$-value. 


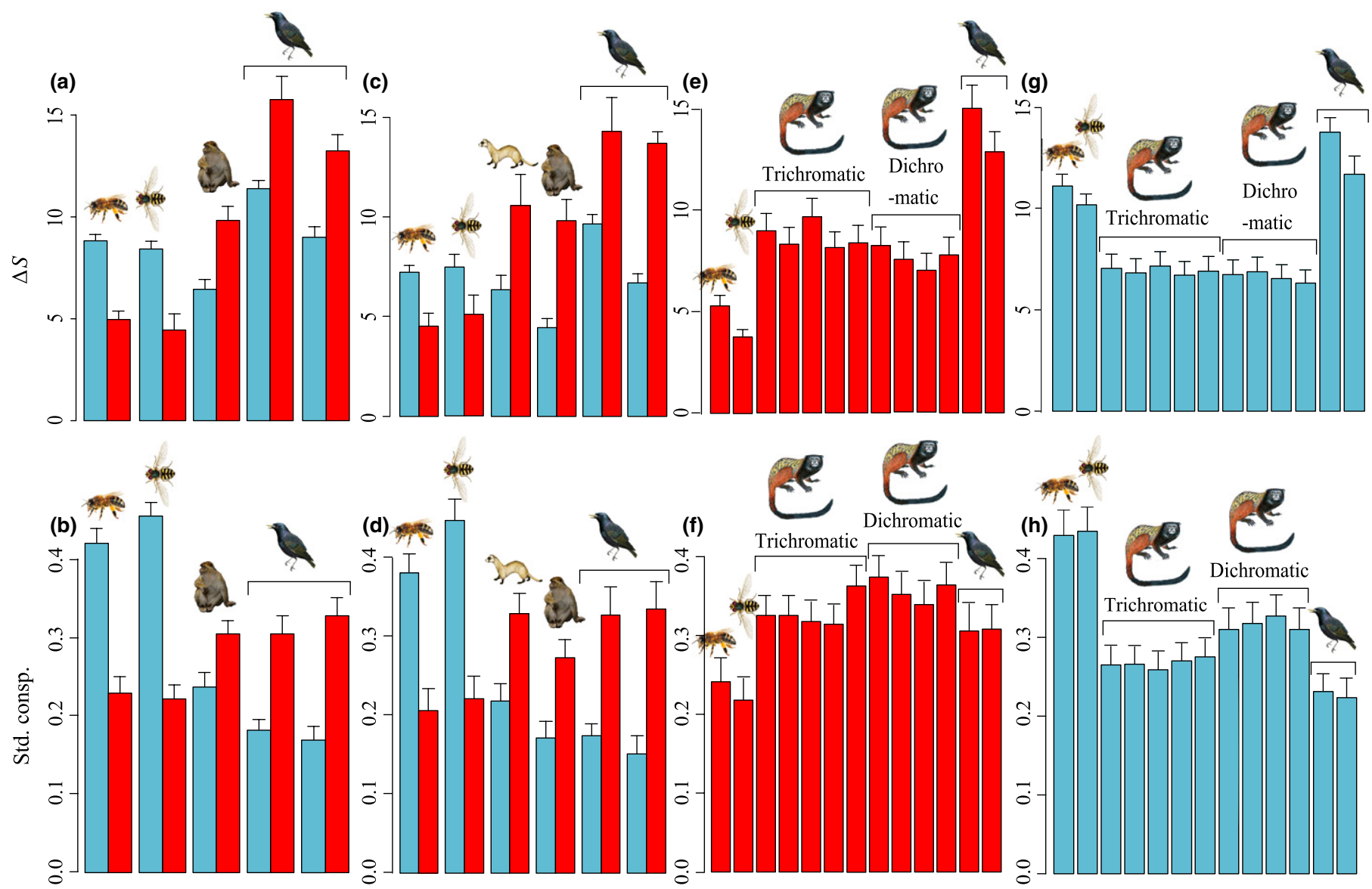

Fig. 1 Comparison of colour conspicuousness of flowers and fruits to pollinators and seed dispersers. (a, b) All flowers and all fruits combined (280 species), (c, d) Spanish data (102 species), (e, f) Brazilian data (111 species) and ( $g$, h) Chilean data (67 species). Bar height indicates mean conspicuousness along with + SE either in just noticeable differences ( $\Delta S$, in JNDs units), that is, calculated with receptor noise limited (RNL) models (a, c, e, g), or in standardized conspicuousness (Std. consp.) estimated using stimulation landscapes (b, $d, f, h)$. Blue bars, flowers; red bars, fruits. A fully captioned version of panel (e) is provided in Supporting Information Fig. S1(a).

helped to illuminate when and how one prevalent pollinator or seed disperser, with its specific visual abilities, can drive plant colour evolution, or can contribute to structure communities by sorting species according to their colouration (e.g. in flowers see Kevan, 1983; Gumbert etal., 1999; Arnold et al., 2009; Dyer et al., 2012; in fruits see Willson \& Thompson, 1982; Burns \& Dalen, 2002; Schmidt et al., 2004; Schaefer et al., 2007; Cazetta et al., 2012). Yet, pollen and seeds are most frequently dispersed by multiple mutualists having differing sensory systems. In this study, we analysed whether and how flower and fruit colours adapt to simultaneously communicate with these multiple, distinct dispersers. We showed that flowers are more conspicuous than fruits to pollinators, and the reverse to seed dispersers. In addition, despite marked differences in the visual systems among pollinating and among seed-dispersing species, flowers are more conspicuous to pollinators than to seed dispersers, and the reverse for fruits.

\section{Adaption to mutualists' visual systems}

In order to demonstrate adaptation to several mutualists, we first predicted that flowers would be more conspicuous to pollinators than fruits would be, and vice versa for fruits and seed dispersers relative to flowers. Our results unambiguously support this prediction. The differential conspicuousness of flowers and fruits to a given perceiver is facilitated by the weak phenotypic integration of colour traits among flowering and fruiting displays. Indeed, even though we found evidence that correlations between flower and fruit colouration are a widespread phenomenon within plant species of the Spanish community, we also showed that there are no strong effects on deeper phylogenetic levels. Thus, genetic correlations and pleiotropy do not appear to be a major constraint in the evolution of flower and fruit colouration. This finding is certainly related to the high versatility of the biosynthetic pathways of plant pigments: minor changes in regulating factors may have profound effects on the resulting colouration (Rausher, 2008). Our results therefore support recent suggestions that colour signals are highly evolvable not only in animals (Endler et al., 2005) but also in plants (Valido et al., 2011; Stournaras et al., 2013).

We were further expecting that the conspicuousness of a given plant structure would be higher to mutualists than to nonmutualists. Again, results with standardized estimates of conspicuousness matched this prediction. Overall, the finding that flower and fruit colours can stimulate the eyes of distinct pollinators and seed 


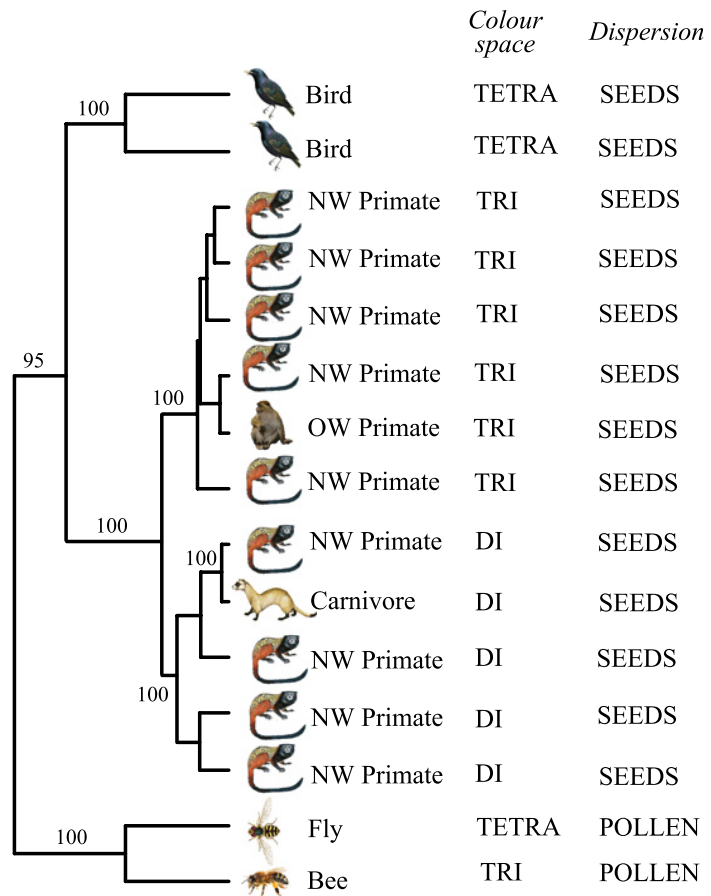

Fig. 2 Tree of similarities among stimulation landscapes reconstructed by comparing standardized conspicuousness of the same $10^{5}$ artificial colour stimuli. Numbers above basal branches indicate bootstrap values. NW, New World; OW, Old World. A fully captioned version is provided in Fig. S1(b).

dispersers, respectively, more strongly than the eyes of unintended animals indicates that these colours are probably signalling adaptations targeted towards distinct plant dispersers.

The higher conspicuousness of a given plant structure to mutualists compared with nonmutualists could originate from selection exerted by mutualists. Flower and fruit phenotypes that are more conspicuous and thus attract more mutualists would have increased fitness, generating differential conspicuousness to mutualists and nonmutualists over evolutionary time. Two conditions for this mechanism to occur are: that mutualists exert convergent and nonindependent selective forces (Iwao \& Rausher, 1997), that is, they have similar perception of colour signals; and that mutualists and nonmutualists have different perception of colours because any increase in conspicuousness to mutualists would otherwise indirectly increase conspicuousness to nonmutualists, independently of whether nonmutualists select plant colours or not. Supporting both conditions, we found that the stimulation landscape is more similar among pollinators and among seed dispersers than between these two groups. Importantly, we showed that functional groups of mutualists exerting similar selective forces on plant colouration should not be defined according to the number of photoreceptor types but according to the perceived similarities.

Selection decreasing conspicuousness to nonmutualists could also generate differential conspicuousness to mutualists and to nonmutualists. Although many flower and fruit antagonists are insects and vertebrates, respectively, various insects such as some butterflies, wasps and bugs are also fruit antagonists, consuming fruit pulp without dispersing seeds, while also serving as vectors for fruit-colonizing fungi (Tewksbury et al., 2008); and many primate and bird species consuming nectar have important deleterious effects for flower reproduction (Riba-Hernandez \& Stoner, 2005). In addition, plant signals could have been shaped to limit detection by the least effective mutualists (Lau \& Galloway, 2004). For example, it is often assumed that red colouration in flowers pollinated by red-sensitive birds has evolved because it reduces detection by bees that are both less effective as pollinators and less sensitive to red (RodríguezGironés \& Santamaría, 2004). The current data do not allow disentangling between selection increasing or decreasing conspicuousness, but the observed differential conspicuousness of flower and fruit colours to intended and unintended perceivers can result from a combination of the two types of selective pressure.

\section{Adaptation through spectral tuning}

Although the perception of colours modelled through photoreceptor signals shares commonalities among dispersers of a given functional group, it also shows substantial differences (Fig. 2). Given the intrinsic constraints that prevent a narrow matching of reflectance spectra with the sensory sensitivities of perceivers, we need to ask how colour signals can be simultaneously tuned to the sensitivity of multiple visual systems. Previous studies showed that minor stepwise changes in reflectance could determine the conspicuousness of flower and fruit colour signals to a given disperser if these changes occur in areas of heightened sensitivity of the perceiver (Chittka \& Menzel, 1992; Schaefer et al., 2007). Provided that bee and fly visual systems share wavelengths with heightened sensitivity, such changes could explain how colours can simultaneously stimulate markedly distinct visual systems.

A synthetic stimulation landscape in which the dimension indicating colour conspicuousness is the sum of standardized conspicuousness to bees and flies identifies the colours that best stimulate simultaneously the perception of the two pollinator groups. Figure 3 illustrates such a landscape and elucidates two important aspects of adaptation to diversified assemblages of pollinators. First, there are several peaks in this synthetic landscape, indicating that different local optima exist in stimulating both flies and bees. If different colours attract simultaneously bees and flies, plants adapting to these insects do not necessarily converge on the same colour signal; a result that can contribute to explaining the pronounced floral colour diversity in angiosperms. Secondly and equally importantly, the fact that small variations in the shape of reflectance spectra can lead to pronounced variations in the summed conspicuousness has important implications for the evolution of adaptations in colour signalling. It suggests that the costly trade-offs typically inherent to adapting to multiple mutualistic partners may not be common in visual communication because small variations in several colours can increase simultaneously the conspicuousness to both bees and flies. This, in combination with the result that several colours can stimulate both bees and flies strongly, may contribute to explaining the ubiquity of diversified interactions in pollen dispersal mutualisms (Waser et al., 1996). 


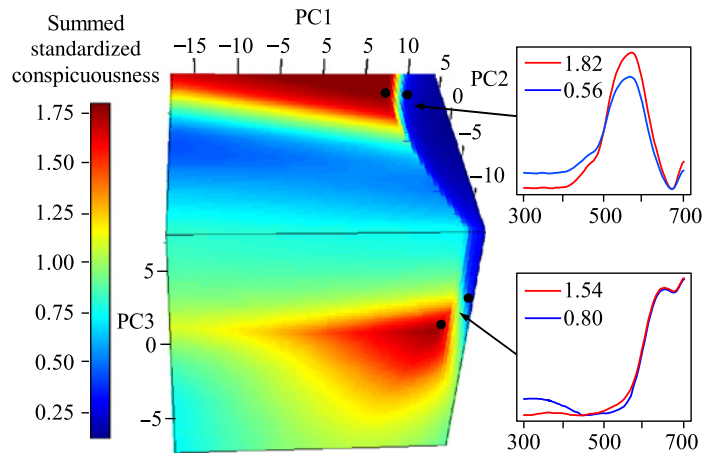

Fig. 3 Stimulation landscape of simultaneous conspicuousness of fruit and flowers to fly and bee visual systems. The landscape was constructed by adding the standardized landscapes of the bee visual system to the landscape of the fly visual system. Only the first three principal components (PCs) of the stimulus space are represented. The summed standardized conspicuousness varies within the interval [0;2] and is unitfree: blue and red colours indicate spectra that are poorly or highly conspicuous to both bees and flies, respectively. Black points indicate pairs of spectra that are physically close - as shown by the physical proximity in the landscape and by the reflectance spectra given in insets (abscissa, wavelengths in nm; ordinate, reflectance) - but are perceptually different - as indicated by the colouration of the landscape and by the values above spectra (indicating the exact value of summed standardized conspicuousness for each reflectance spectrum).

Major changes in conspicuousness resulting from minor spectral variations also explain how flower and fruit colours could have reduced conspicuousness to antagonists or to ineffective mutualists. In addition, signals reflecting most of the light at one extreme of the visible light spectrum, to which only effective mutualists are sensitive, could also contribute to stimulating mutualists more than nonmutualists. Supporting this mechanism, there were more fruits than flowers in our data sets with a deeply saturated red colour that is highly conspicuous to birds (Fig. S2).

\section{Adaptation, colour preferences and conspicuousness}

Studies investigating possible adaptations of plant colouration to animal dispersers analysed how hues segregate to different groups of animals; which is an indirect approach to analyse associations between plant colouration and colour selection (e.g. GautierHion etal., 1985; Arnold etal., 2009; Campbell et al., 2010). While hues can be associated with specific groups of dispersers, there is little support that this association is driven by animals' colour preferences. Often, there is marked variation in colour preferences among species, populations and even individuals (McCall \& Primack, 1992) and preferences are even transient within individuals (Willson, 1994). This variation arises because colour preferences (both innate and learned) can be themselves adaptive, that is, are shaped to facilitate recognition of beneficial objects (Raine \& Chittka, 2007; Palmer \& Schloss, 2010), and are thus context-dependent. For example, a flower can be profitable or not to a given pollinator depending on competition with other pollinators (Chittka \& Waser, 1997; Valido et al., 2002), availability of alternative plant resources (Ghazoul, 2004), and environmental as well as genetic factors influencing the production of rewards by plants (Mitchell, 2004) or colour signalling (e.g. herbivores influencing frequency of colour morphs; Irwin et al., 2003). Studying the association between hues and groups of perceivers may thus not be optimal to evaluate the adaptation of plant colouration to dispersers, because a lack of association could be a result of grouping perceivers at the wrong level (typically at species level when preferences differ between populations; Lazaro etal., 2008), while a positive association could be driven be adaptation in perceivers but not in signallers.

In contrast to colour preferences, the perception of colours as coded at the eye level is much more stable across perceivers (Briscoe \& Chittka, 2001; Osorio \& Vorobyev, 2008). Indeed, the number and sensitivities of photoreceptor types are most frequently adapted for 'general-purpose' vision within a given environment, which constrains adaption to a specific visual task (Osorio \& Vorobyev, 2008). As a consequence, diversification in plant colouration should postdate diversification of photoreceptors (Chittka, 1997), meaning that a match between flower or fruit colours and dispersers' perception of colours probably originates from an adaptive tuning of plant colouration. This explains why those studies interested in colour conspicuousness or colour diversity with regard to the discrimination abilities of animal dispersers (two aspects of visual communication determined mainly at the eye level) unambiguously support adaptation of flower and fruit colouration to animal mutualists (this study; Chittka \& Menzel, 1992; Lomáscolo et al., 2010; Dyer et al., 2012; Shrestha et al., 2013). One exception is the study by Lomáscolo \& Schaefer (2010). These authors found that, although bird-eaten and primate-eaten fruits can be well discriminated by birds and primates based on colouration, both types of fruits are more conspicuous to birds than to primates. This and our own findings together suggest that, in general, the colouration of flowers and fruits is adaptively conspicuous to pollinators and seed dispersers, respectively, but above a minimal threshold of conspicuousness, different colours can be selected (there are several peaks of simultaneous conspicuousness; see Fig. 3) depending on local colour preferences of mutualists or on factors unrelated to communication.

\section{Considerations}

We caution against generalizing our conclusions too widely. We selected the Spanish and the two South American communities in this study because the identity of the main pollen and seed dispersers allowed a balanced design with trichromatic and tetrachromatic perceivers within each type of dispersal service. These communities show a robust pattern of adaptation, but cannot represent all possible interactions between plants and dispersers. For example, birds can also contribute substantially to pollination, reptiles sometimes visit flowers and fruits, and insects can disperse seeds of fleshy fruits (Duthie et al., 2006). While more studies are clearly needed in order to assess whether our results and the suggested mechanisms of adaptation apply to other communities and ecosystems, the concordant results between the Spanish and the two South American communities suggest that adaptation of flower and fruit colours to multiple, distinct mutualists may be widespread. 


\section{Conclusions}

Since Aristotle, it has been paradigmatically assumed that flower colours are adapted to attract pollinators (Chittka, 1997; Lee, 2007). A growing body of literature has shown, however, how interactions with multiple species such as those occurring between most plants and animal dispersers translate into disparate selective pressures (Thompson, 2005; Guimarães et al., 2011). Thus, the degree of adaptations in generalized plantanimal mutualisms is contentious (Waser et al., 1996; Fenster et al., 2004). Here, we showed that subtle adjustments in colour stimuli allow broad-band colour stimuli to match broad-band receptor sensitivities of multiple mutualists. These adjustments can have important perceptual effects, allowing adaptation of flower and fruit colour signals. This study suggests that adaptation to a specific set of mutualists can occur more frequently than currently acknowledged in colour signalling, even in megadiversified networks of mutualistic interactions.

\section{Acknowledgements}

We thank C. Wurmitzer, J. Jansen, R. Medel, E. Cazetta, and M. Galetti for help in collecting data on flower and fruit colours. This project was funded by a bilateral agreement between Ministerio de Ciencia e Innovación and Deutscher Akademischer Austausch Dienst (HA2006-0038 and DE2009-0091). J.P.R. and A.V. are fellows of the Volkswagen Foundation and the 'Ramón y Cajal' postdoctoral research programme (Ministerio de Ciencia e Innovación; RYC-2007-00620), respectively, and H.M.S. is supported by the DFG (Scha 1008/5-1). The Consejería de Medio Ambiente, Junta de Andalucía, provided facilities, access and sampling permits.

\section{References}

Arnold SEJ, Savolainen V, Chittka L. 2009. Flower colours along an alpine altitude gradient, seen through the eyes of fly and bee pollinators. ArthropodPlant Interactions 3: 27-43.

Bascompte J, Jordano P. 2007. Plant-animal mutualistic networks: the architecture of biodiversity. Annual Review of Ecology Evolution and Systematics 38: 567-593.

Briscoe AD, Chittka L. 2001. The evolution of color vision in insects. Annual Review of Entomology 46: 471-570.

Burns KC, Dalen JL. 2002. Foliage color contrasts and adaptive fruit color variation in a bird-dispersed plant community. Oikos 96: 463-469.

Campbell DR, Bischoff M, Lord JM, Robertson AW. 2010. Flower color influences insect visitation in alpine New Zealand. Ecology 91: 26382649.

Campell DR, Aldridge G. 2006. Floral biology in hybrid zones. In: Harder LD, Barrett SCH, eds. Ecology and evolution of flowers. Oxford, UK: Oxford University Press, 326-345.

Cazetta E, Galetti M, Rezende E, Schaefer HM. 2012. On the reliability of visual communication in vertebrate-dispersed fruits. Journal of Ecology 100 : 277-286.

Cazetta E, Schaefer HM, Galetti M. 2009. Why are fruits colorful? The relative importance of achromatic and chromatic contrasts for detection by birds. Evolutionary Ecology 23: 233-244.

Chittka L. 1997. Bee color vision is optimal for coding flower color, but flower colors are not optimal for being coded: why? Israel Journal of Plant Sciences 45: $115-127$.
Chittka L, Menzel R. 1992. The evolutionary adaptation of flower colours and the insect pollinators' colour vision. Journal of Comparative Physiology A 171: $171-181$.

Chittka L, Waser NM. 1997. Why red flowers are not invisible to bees. Israel Journal of Plant Sciences 45: 169-183.

Duthie C, Gibbs G, Burns KC. 2006. Seed dispersal by weeta. Science 311: 1575.

Dyer AG, Boyd-Gerny S, McLoughlin S, Rosa MGP, Simonov V, Wong BBM. 2012. Parallel evolution of angiosperm colour signals: common evolutionary pressures linked to hymenopteran vision. Proceedings of the Royal Society of London Series B: Biological Sciences 279: 3606-3615.

El Alami A, Chait A. 2012. Seasonal variation in activity budget and diet of the endangered barbary macaque (Macaca sylvanus) in the tourist valley of Ouzoud, central High Atlas, Morocco. Mammalia 76: 245-250.

Endler JA, Westcott DA, Madden JR, Robson T. 2005. Animal visual systems and the evolution of color patterns: sensory processing illuminates signal evolution. Evolution 59: 1795-1818.

Fenster CB, Armbruster WS, Wilson P, Dudash MR, Thomson JD. 2004. Pollination syndromes and floral specialization. Annual Review of Ecology and Systematics 35: 375-403.

Gautier-Hion A, Duplantier J-M, Quris R, Feer F, Sourd C, Decoux J-P, Dubost G, Emmons L, Erard C, Hecketsweiler P et al. 1985. Fruit characters as a basis of fruit choice and seed dispersal in a tropical forest vertebrate community. Oecologia 65: 324-337.

Ghazoul J. 2004. Alien abduction: disruption of native plant-pollinator interactions by invasive species. Biotropica 36: 156-164.

Guimarães PR Jr, Jordano P, Thompson JN. 2011. Evolution and coevolution in mutualistic networks. Ecology Letters 14: 877-885.

Gumbert A, Kunze J, Chittka L. 1999. Floral colour diversity in plant communities, bee colour space and a null model. Proceedings of the Royal Society of London Series B: Biological Sciences 266: 1711-1716.

Hadfield JD. 2010. MCMC methods for multi-response generalized linear mixed models: the MCMCglmm R package. Journal of Statistical Software 33: 1-22.

Hansen TF. 2003. Is modularity necessary for evolvability? Remarks on the relationship between pleiotropy and evolvability. Biosystems 69: 83-94.

Hempel DI, Giurfa M, Vorobyev MV. 2001. Detection of coloured patterns by honeybees through chromatic and achromatic cues. Journal of Comparative Physiology A 187: 215-224.

Herrera CM. 1988. Pollination relationships in southern spanish mediterranean shrublands. Journal of Ecology 76: 274-287.

Herrera CM. 1995. Plant-vertebrate seed dispersal systems in the mediterranean: ecological, evolutionary, and historical determinants. Annual Review in Ecology and Systematics 26: 705-727.

Irwin RE, Strauss SY, Storz S, Emerson A, Guibert G. 2003. The role of herbivores in the maintenance of a flower color polymorphism in wild radish. Ecology 84: 1733-1743.

Iwao K, Rausher MD. 1997. Evolution of plant resistance to multiple herbivores: quantifying diffuse coevolution. American Naturalist 149: 316-355.

Jaaskelainen T, Parkkinen J, Toyooka S. 1990. Vector-subspace model for color representation. Journal of the Optical Society of America A 7: 725-730.

Jacobs GH. 2008. Primate color vision: a comparative perspective. Visual Neuroscience 25: 619-633.

Kelber A, Vorobyev M, Osorio D. 2003. Animal colour vision: behavioural tests and physiological concepts. Biological Reviews 78: 81-118.

Kevan PG. 1983. Floral colours through the insect eye: what they are and what they mean. In: Jones CE, Little RJ, eds. Handbook of experimental pollination biology. New York, NY, USA: Van Nostrand Reinhold, 329-352.

Lau JA, Galloway LF. 2004. Effects of low-efficiency pollinators on plant fitness and floral trait evolution in Campanula americana (Campanulaceae). Oecologia 141: $577-583$.

Lazaro A, Hegland SJ, Totland O. 2008. The relationships between floral traits and specificity of pollination systems in three Scandinavian plant communities. Oecologia 157: 249-257.

Lee D. 2007. Nature's palette: the science of plant color. Chicago, IL, USA: Chicago University Press.

Lomáscolo SB, Levey DJ, Kimball RT, Bolker BM, Alborn HT. 2010. Dispersers shape fruit diversity in Ficus (moraceae). Proceedings of the National Academy of Sciences, USA 107: 14668-14672. 
Lomáscolo SB, Schaefer HM. 2010. Signal convergence in fruits: a result of selection by frugivores? Journal of Evolutionary Biology 23: 614-624.

McCall C, Primack RB. 1992. Influence of flower characteristics, weather, time of the day, and season on insect visitation rates in three plant communities. American Journal of Botany 79: 434-442.

Mitchell RJ. 2004. Heritability of nectar traits: why do we know so little? Ecology 85: $1527-1533$.

Osorio D, Vorobyev M. 2005. Photoreceptor spectral sensitivities in terrestrial animals: adaptations for luminance and colour vision. Proceedings of the Royal Society of London Series B: Biological Sciences 272: 1745-1752.

Osorio D, Vorobyev M. 2008. A review of the evolution of animal colour vision and visual communication signals. Vision Research 48: 2042-2051.

Palmer SE, Schloss KB. 2010. An ecological valence theory of human color preference. Proceedings of the National Academy of Sciences, USA 107: 8877-8882.

R Development Core Team. 2011. R: a language and environment for statistical computing. Vienna, Austria: R Foundation for Statistical Computing.

Raine NE, Chittka L. 2007. The adaptive significance of sensory bias in a foraging context: floral colour preferences in the bumblebee Bombus terrestris. PLOS ONE 2: e556.

Rausher MD. 2008. Evolutionary transitions in floral color. International Journal of Plant Sciences 169: 7-21.

Regan BC, Julliot C, Simmen B, Vienot F, Charles-Dominique P, Mollon JD. 2001. Fruits, foliage and the evolution of primate colour vision. Philosophical Transactions of the Royal Society of London. Series B, Biological Sciences 356: 229-283.

Renoult JP, Courtiol A, Schaefer HM. 2013. A novel framework to study colour signaling to multiple species. Functional Ecology 27: 718-729.

Riba-Hernandez P, Stoner KE. 2005. Massive destruction of Symphonia globulifera (Clusiaceae) flowers by Central American spider monkeys (Ateles geoffroyi). Biotropica 37: 274-278.

Rodríguez-Gironés MA, Santamaría L. 2004. Why are so many bird flowers red? PLoS Biology 2: e350.

Schaefer HM, McGraw K, Catoni C. 2008. Birds use fruit colour as honest signal of dietary antioxidant rewards. Functional Ecology 22: 303-310.

Schaefer HM, Ruxton G. 2011. Plant-animal communication. Oxford, UK: Oxford University Press.

Schaefer HM, Schaefer V, Vorobyev M. 2007. Are fruit colors adapted to consumer vision and birds equally efficient in detecting colorful signals? American Naturalist 169: S159-S169.

Schmidt V, Schaefer HM, Winkler H. 2004. Conspicuousness, not colour as foraging cue in plant-animal signalling. Oikos 106: 551-557.

Shrestha M, Dyer AG, Boyd-Gerny S, Wong BBM, Burd M. 2013. Shades of red: bird-pollinated flowers target the specific colour discrimination abilities of avian vision. New Phytologist 198: 301-310.

Spaethe J, Tautz J, Chittka L. 2001. Visual constraints in foraging bumblebees: flower size and color affect search time and flight behavior. Proceedings of the National Academy of Sciences, USA 98: 3898-3903.

Stobbe N, Schaefer HM. 2008. Enhancement of chromatic contrast increases predation risk for striped butterflies. Proceedings of the Royal Society of London Series B: Biological Sciences 275: 1535-1541.

Stournaras KE, Lo E, Böhning-Gaese K, Cazetta E, Dehling DM, Schleuning M, Stoddard MC, Donoghue MJ, Prum RO, Schaefer HM. 2013. How colorful are fruits? Limited color diversity in fleshy fruits on local and global scales. New Phytologist 198: 617-629.
Strauss SY, Whittall JB. 2006. Non-pollinator agents of selection on floral traits. In: Harder LD, Barrett SCH, eds. Ecology and evolution of flowers. Oxford, UK: Oxford University Press, 120-139.

Tewksbury JJ, Reagan KM, Machnicki NJ, Carlo TA, Haak DC, Penaloza ALC, Levey DJ. 2008. Evolutionary ecology of pungency in wild chilies. Proceedings of the National Academy of Sciences, USA 105: 11808-11811.

Thompson JN. 2005. The geographic mosaic of coevolution. Chicago, IL, USA: University of Chicago Press.

Valido A, Dupont YL, Hansen DM. 2002. Native birds and insects, and introduced honey bees visiting Echinium wildpretii (Boraginaceae) in the Canary Islands. Acta Oecologia 23: 413-419.

Valido A, Schaefer HM, Jordano P. 2011. Colour, design and reward: phenotypic integration of fleshy fruit displays. Journal of Evolutionary Biology 24: 751-760.

Valverde JA. 1967. Estructura de una comunidad de vertebrados terrestres. Monografias de la Estación Biologica de Doñana 1: 1-218.

van Hateren JH. 1993. Spatial, temporal and spectral preprocessing for color-vision. Proceedings of the Royal Society of London Series B: Biological Sciences 251: 61-68.

Vorobyev M, Osorio D. 1998. Receptor noise as a determinant of colour thresholds. Proceedings of the Royal Society of London Series B: Biological Sciences 265: 351-358.

Waser NM, Chittka L, Price MV, Williams NM, Ollerton J. 1996. Generalization in pollination systems, and why it matters. Ecology 77: 10431060 .

Willson MF. 1994. Fruit choices by captive American Robins. Condor 96: 494502.

Willson MF, Thompson JN. 1982. Phenology and ecology of color in bird-dispersed fruits or why some fruits are red when they are "Green". Canadian Journal of Botany 60: 701-713.

\section{Supporting Information}

Additional supporting information may be found in the online version of this article.

Fig. S1 Fully captioned version of Figs 1(e) and 2.

Fig. S2 Distribution of fruit and flower colours in the bee, fly, macaque and bird colour spaces.

Methods S1 Supplementary methods for estimating conspicuousness.

Methods S2 Phylogenetic relationships among the 102 Spanish plant species.

Please note: Wiley Blackwell are not responsible for the content or functionality of any supporting information supplied by the authors. Any queries (other than missing material) should be directed to the New Phytologist Central Office. 
(a)

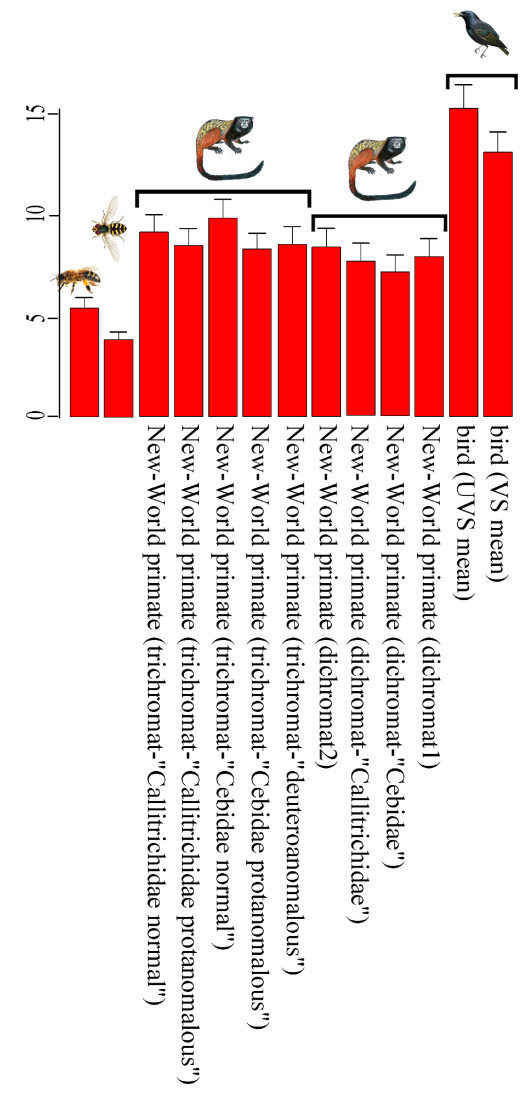

(b)

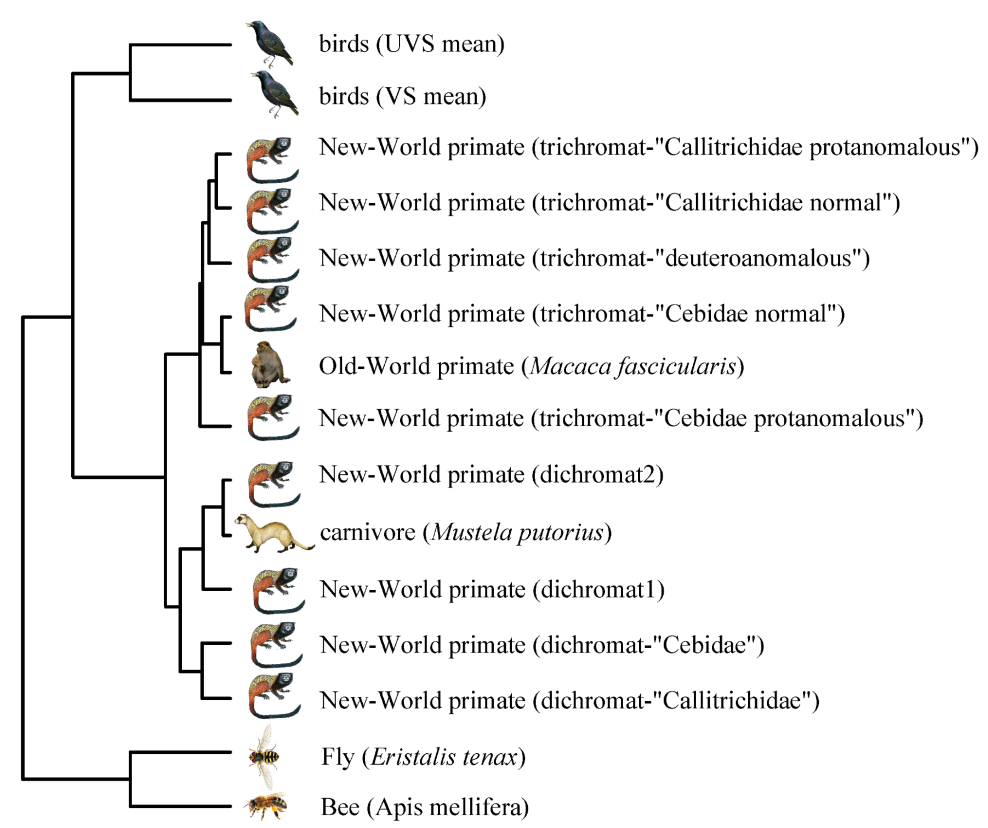

Fig. S1 Fully captioned version of Figs 1(e), 2. 

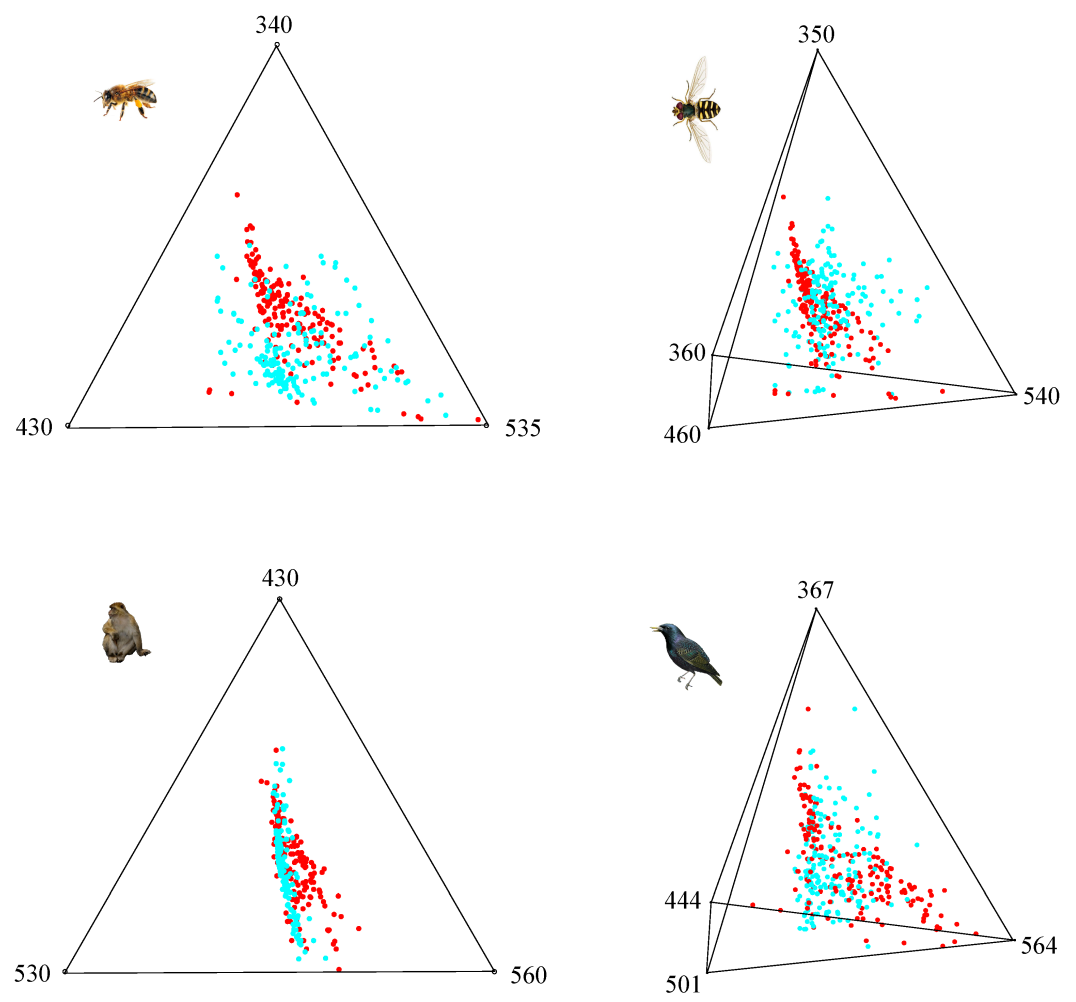

Fig. S2 Distribution of flower (red) and fruit (blue) colours in the bee, fly, macaque and UVS bird chromaticity diagrams. Photoreceptors are labelled by their wavelength of maximal sensitivity (see Table 1 in Methods S1). Diagrams are extracted from a photoreceptor contrast space, indicating that the green environmental background lies at the centre of the diagrams. The conspicuousness of a plant item is given by its distance to the centre of the diagram. Even though flower and fruit colours show different distribution among and between diagrams (for a discussion on these differences; see Osorio \& Vorobyev, 2008), no particular flower or fruit colour is obviously driving the higher averaged conspicuousness of flower colours to pollinators and of fruit colours to seed dispersers (here, it is important to realise that the spread is indicating colour diversity, not conspicuousness; see Endler \& Mielke, 2005). One exception may be the fruit colours in the bird diagram: a relatively high number of fruits that stimulate almost exclusively the $564 \mathrm{~nm}$ photoreceptor, which corresponds to highly saturate red fruits, may increase the average conspicuousness of fruits in comparison to flowers. 


\section{References}

Arnold SEJ, Savolainen V, Chittka L. 2009. Flower colours along an alpine altitude gradient, seen through the eyes of fly and bee pollinators. Arthropod-Plant Interactions 3: 27-43.

Brembs B, de Ibarra NH. 2006. Different parameters support generalization and discrimination learning in Drosophila at the flight simulator. Learning \& Memory 13: 629-637.

Calderone JB, Jacobs GH. 2003. Spectral properties and retinal distribution of ferret cones. Visual Neuroscience 20: 11-17.

Davies TJ, Barraclough TG, Chase MW, Soltis PS, Soltis DE, Savolainen V. 2004. Darwin's abominable mystery: Insights from a supertree of the angiosperms. Proceedings of the National Academy of Sciences, USA 101: 1904-1909.

Defrize J, Thery M, Casas J. 2010. Background colour matching by a crab spider in the field: A community sensory ecology perspective. Journal of Experimental Biology 213: $1425-1435$.

Endler JA, Mielke PW. 2005. Comparing entire colour patterns as birds see them. Biological Journal of the Linnean Society 86: 405-431.

Fukushi T. 1994. Colour perception of single and mixed monochromatic lights in the blowfly Lucilia cuprina. Journal of Comparative Physiology A 175: 15-22.

Govardosvskii VI, Fyhrquist N, Reuter T, Kuzmin DG, Donner K. 2000. In search of the visual pigment template. Visual Neuroscience 17: 509-528.

Hempel DI, Giurfa M, Vorobyev MV. 2001. Detection of coloured patterns by honeybees through chromatic and achromatic cues. Journal of Comparative Physiology A 187: 215-224.

Horridge GA, Mimura K, Tsukahara Y. 1975. Fly photoreceptors .2. Spectral and polarized-light sensitivity in drone fly Eristalis. Proceedings of the Royal Society of London Series B 190: 225-237.

Jacobs GH. 2008. Primate color vision: A comparative perspective. Visual Neuroscience 25.

Kelber A, Vorobyev M, Osorio D. 2003. Animal colour vision : Behavioural tests and physiological concepts. Biological Reviews 78: 81-118.

Maloney LT. 1986. Evaluation of linear models of surface spectral reflectance with small numbers of parameters. Journal of the Optical Society of America A 6: 318-322.

Menzel R, Backhaus W 1991. Colour vision in insects. In: P. Gouras ed. Vision and visual dysfunction. Vi. Perception of colour. Houndsmill, UK: Macmillan Press, 262-293.

Morante J, Desplan C. 2008. The color-vision circuit in the medulla of Drosophila. Current Biology 18: 553-565.

Osorio D, Smith AC, Vorobyev M, Buchanan-Smith HM. 2004. Detection of fruit and the selection of primate visual pigments for color vision. American Naturalist 164: 696708.

Osorio D, Vorobyev M. 2008. A review of the evolution of animal colour vision and visual communication signals. Vision Research 48: 2042-2051. 
Prokopy RJ, Economopoulos AP, McFadden MW. 1975. Attraction of wild and laboratorycultured Dacus oleae flies to small rectangles of different hues, shades, and tints. Entomologia Experimentalis et Applicata 18: 141-152.

Renoult JP, Courtiol A, Schaefer HM. 2013. A novel framework to study colour signaling to multiple species. Functional Ecology 27: 718-729.

Sutherlands JP, Sullivan MS, Poppy GM. 1999. The influence of floral character on the foraging behaviour of the hoverfly, Episyrphus balteatus. Entomologia Experimentalis et Applicata 93: 157-164.

Troje N. 1993. Spectral categories in the learning-behavior of blowflies Zeitschrift Fur Naturforschung C-A Journal of Biosciences 48: 96-104.

Vorobyev M, Brandt R, Peitsch D, Laughlin SB, Menzel R. 2001. Colour thresholds and receptor noise: Behaviour and physiology compared. Vision Research 41: 639-653.

Vorobyev M, Osorio D. 1998. Receptor noise as a determinant of colour thresholds. Proceedings Royal Society of London B 265: 351-358.

Wilkström N, Savolainen V, Chase MW. 2001. Evolution of the angiosperms: Calibrating the family tree. Proceedings of the Royal Society of London B 268: 2211-2220.

Wyszecki G, Stiles WS. 1982. Color science: Concepts and methods, quantitative data and formulae. NewYork, NY, USA: Wiley.

Yamaguchi S, Desplan C, Heisenberg M. 2010. Contribution of photoreceptor subtypes to spectral wavelength preference in Drosophila. Proceedings of the National Academy of Science of the USA 107: 5634-5639. 
Methods S1 Supplementary methods for estimating conspicuousness.

\section{Receptor Noise Limited models}

We first used Receptor Noise Limited models (RNL; Vorobyev \& Osorio, 1998) to estimate colour contrasts between a signalling stimulus (flower or fruit reflectance spectrum) and the background stimulus (average leaf spectrum). For each photoreceptor $i$ we calculated the adapted quantum catch $q_{i}$ as:

$$
q_{i}=\frac{\int_{300}^{700} S(\lambda) I(\lambda) R_{i}(\lambda) d \lambda}{\int_{300}^{700} B(\lambda) I(\lambda) R_{i}(\lambda) d \lambda},
$$

where $S(\lambda), B(\lambda), I(\lambda)$ and $R_{i}(\lambda)$ correspond to the reflectance spectrum of the stimulus (fruits or flowers), the background (leave), the illuminant spectrum (CIE D65), and the photoreceptor sensitivity function, respectively.

Photoreceptor sensitivity functions were built using original templates from Govardosvskii et al. (2000) and wavelengths of maximal sensitivity except for flies (Table 1 in Methods S1). For flies, we used sensitivity functions originally published for the hoverfly (Eristalis tenax)'s photoreceptors (Horridge et al., 1975) because Govardosvskii's templates did not allow reproducing the shape of receptor sensitivities. For bees, we used wavelengths of maximal sensitivity published for the honeybee Apis mellifera (Menzel \& Backhaus, 1991). For birds, we reconstructed sensitivity functions corresponding to both ultraviolet- and violetsensitive visual systems using data provided in Endler \& Mielke (2005). For carnivores, we used values of maximal sensitivity published for the matern Mustela putorius (Calderone \& Jacobs, 2003). Photoreceptor sensitivity functions of the Barbary macaque were reconstructed 
using data from the crab-eating macaque Macaca fascicularis (Jacobs, 2008). Because most New-World primates exhibit polymorphism at a X-chromosome opsin gene, six visual systems (either dichromatic or trichromatic) can theoretically be found within the same population (Jacobs, 2008). In addition, photoreceptor sensitivities differ between Callitrichidae (e.g., marmosets, tamarins) and Cebidae (Cebus, squirrel monkeys) families, leading to twelve possible visual systems in polymorphic New-World primates (Jacobs, 2008). We included nine of these twelve systems in our analyses because three of them were almost redundant (Table 1 in Methods S1). Sensitivity functions were built for each system using data on maximal sensitivity provided by Osorio et al. (2004).

Table 1 in Methods S1. Wavelengths of maximal sensitivity for each photoreceptor used to build photoreceptor sensitivity functions $R_{i}(\lambda)$. Photoreceptors are ordered according to their wavelength of maximal sensitivity, with the shortest wavelength corresponding to the smallest $i$ index.

\begin{tabular}{|c|c|c|c|c|c|}
\hline \multirow{2}{*}{ Animal model } & \multicolumn{4}{|c|}{ Photoreceptor $i$} & \multirow{2}{*}{ Ref. } \\
\hline & 1 & 2 & 3 & 4 & \\
\hline Bees (Apis mellifera) & 340 & 430 & 535 & & $\begin{array}{c}\text { (Menzel \& Backhaus, } \\
\text { 1991) }\end{array}$ \\
\hline Fly (Eristalis tenax) & 330 & 340 & 460 & 540 & (Horridge et al., 1975) \\
\hline Birds (UVS mean) & 367 & 444 & 501 & 564 & (Endler \& Mielke, 2005) \\
\hline Birds (VS mean) & 412 & 452 & 505 & 565 & (Endler \& Mielke, 2005) \\
\hline Marten (Mustela putorius) & 430 & 558 & & & (Endler \& Mielke, 2005) \\
\hline Old-World primate (Macaca fascicularis) & 430 & 530 & 560 & & (Jacobs, 2008) \\
\hline New-World primate (dichromat1) & 430 & & 553 & & (Osorio et al., 2004) \\
\hline New-World primate (dichromat2) & 430 & & & 562 & (Osorio et al., 2004) \\
\hline New-World primate (dichromat-"Callitrichidae") & 430 & 543 & & & (Osorio et al., 2004) \\
\hline New-World primate (dichromat-"Cebidae") & 430 & 535 & & & (Osorio et al., 2004) \\
\hline New-World primate (trichromat-"deuteroanomalous") & 430 & & 553 & 562 & (Osorio et al., 2004) \\
\hline New-World primate (trichromat-"Cebidae normal") & 430 & 535 & & 562 & (Osorio et al., 2004) \\
\hline New-World primate (trichromat-"Cebidae protanomalous") & 430 & 535 & 550 & & (Osorio et al., 2004) \\
\hline New-World primate (trichromat-"Callitrichidae normal") & 430 & 543 & & 562 & (Osorio et al., 2004) \\
\hline
\end{tabular}


Applying the RNL model to flies supposes that all four R7p, R7y, R8p and R8y receptors feed an unspecified opponent function. The RNL model thereby differs from another model proposed to explain colour vision in flies and that has been previously used in ecological studies (e.g., see Arnold et al., 2009; Defrize et al., 2010). Indeed, Troje (1993) proposed that flies classify stimuli in four different colour categories, and that stimuli can be discriminated only if they belong to distinct categories. We did not use this model of categorical colour vision because it is not supported by several behavioural and anatomical data. For example, Sutherlands et al. (1999) showed that the hoverfly Episyrphus balteatus has a marked preference for blue over yellow-green artificial flowers, which is unlikely to originate from the very small difference in achromatic contrast between both stimuli. According to Troje's model, however, the two stimuli lie well within the same colour category and thus they should not be distinguishable. Similar behavioural evidences for discrimination abilities within colour categories of Troje's model can be found in Prokopy et al.(1975) for a tephritid fly, and in Brembs \& de Ibarra (2006) and Yamaguchi et al. (2010) for Drosophila. By contrast, Brembs \& de Ibarra (2006) while applying the RNL models found that their behavioural results on colour discrimination best matched predictions made when using inputs from the three R7y, R8p, R8y receptors. Similarly, Fukushi (1994) supports a \{R7y, R8p, R8y\} trichromatic colour vision modelled using a Maxwell triangle. Both studies, however, did not include UV-rich stimuli, meaning that the UV-sensitive $\mathrm{R} 7 \mathrm{p}$ receptor was not stimulated. This explains why Fukushi (1994) even did not attempt to model colour vision including inputs from this photoreceptor. Yet more recent studies clearly showed that R7p influences colour vision. Yamaguchi et al. (2010) found that mutant flies with only R7 receptors have a strong 
preference for blue when having the choice between blue and UV. This can be explained only if R7y and R7p are connected to each other by an opponent mechanism; an explanation further supported anatomically by the existence of neurons that contact R7y to R7p and R8y to R8p (Morante \& Desplan, 2008). From these results, it appears that a chromaticity diagram should be most reliably modelled by including inputs from all four R7p, R7y, R8y and R8p receptors.

We used the logarithmic version of the RNL model in which the adapted quantum catches calculated with Equation 1 are log-transformed (Vorobyev et al., 2001). Then, each photoreceptor type is assigned a noise factor $\mathrm{e}_{\mathrm{i}}$ depending on the Weber fraction and the relative density of the photoreceptor type (see Kelber et al., 2003) for the formulae and Table 2 in Methods $\mathrm{S} 1$ for values of $\mathrm{e}_{\mathrm{i}}$ ). In this study, we assumed photopic viewing condition, i.e. sufficiently bright illumination for the Weber law to hold (Vorobyev et al., 2001). The noise factor is therefore assumed to be independent of the perceived stimulus and is given by the neural noise only.

Table 2 in Methods S1. Photoreceptor noise factor $\mathrm{e}_{\mathrm{i}}$.

\begin{tabular}{lcc}
\hline Animal model & noise factor $\mathrm{e}_{\mathrm{i}}$ & Ref. \\
\hline Bees (Apis mellifera) & $\{0.13,0.06,0.12\}$ & (Hempel et al., 2001) \\
Fly (Eristalis tenax) & $\{0.1,0.65,0.1,0.65\}$ & $\begin{array}{c}\text { (Brembs \& de Ibarra, } \\
\text { 2006) }\end{array}$ \\
Birds (UVS mean) & $\{0.1,0.07,0.07,0.05\}$ & (Vorobyev \& Osorio, \\
& & 1998)
\end{tabular}




\section{Stimulation landscapes}

In order to model stimulation landscapes, we first defined a chromaticity diagram $\left\{q^{c} 1, \ldots, q^{c_{i}}\right\}$

by removing the achromatic dimension of the photoreceptor contrast space $\left\{q_{1}, \ldots, q_{\mathrm{i}}\right\}$ :

$$
q^{c}{ }_{i}=\frac{q_{i}}{\sum q_{i}}
$$

In this model, the background location lies at the centre of the diagram. In a segmental diagram for dichromatic vision, the coordinate of the stimulus location is given by:

$$
x=\frac{1}{\sqrt{2}}\left(q_{2}^{c}-q_{1}^{c}\right)
$$

In the two-dimensional diagram for trichromatic vision, coordinates are given by:

$$
\begin{gathered}
x=\frac{1}{\sqrt{2}}\left(q^{c}{ }_{3}-q^{c}{ }_{2}\right), \\
y=\frac{\sqrt{2}}{\sqrt{3}}\left(q^{c}{ }_{1}-\frac{q^{c}{ }_{3}+q^{c}{ }_{3}}{2}\right) .
\end{gathered}
$$

Last, in the three-dimensional diagram for tetrachromatic vision, coordinates are given by:

$$
\begin{gathered}
x=\frac{1}{\sqrt{2}}\left(q^{c}{ }_{4}-q^{c}{ }_{3}\right), \\
y=\frac{\sqrt{2}}{\sqrt{3}}\left(q_{2}^{c}-\frac{q^{c}{ }_{3}+q^{c}{ }_{4}}{2}\right), \\
z=\frac{\sqrt{3}}{2}\left(q^{c}{ }_{1}-\frac{q^{c}{ }_{2}+q^{c}{ }_{3}+q^{c}{ }_{4}}{3}\right) .
\end{gathered}
$$


The conspicuousness $C$ of the stimulus is eventually given by the Euclidean distance between the stimulus and the background locations in the chromaticity diagram.

A stimulation landscape is built by treating $C$ as a variable, which is added to a spectral space. One location in a spectral space corresponds to one reflectance spectrum (Renoult et al., 2013). Contrary to the variable $C$, the spectral space if the same for the fifteen groups of perceivers studied. Reflectance spectra of natural objects are typically smoothlyshaped, which is indicative of high correlation between the reflectance of adjacent wavelengths. As a consequence, a spectral space is low-dimensional. We applied a principal component analysis (PCA) on the full dataset of reflectance spectra to reduce the dimensionality of the spectral space. PCA was performed with reflectance spectra normalised to have integrals of constant value (Maloney, 1986). Keeping six principle components and inverting the PCA procedure, we were able to reconstruct a dataset of reflectance spectra that was 'perceptually similar' to the original dataset when seen by birds; the animals with the best capacities in colour discrimination among the fifteen types of perceivers studied. Here, 'perceptually similar' means that more than $99 \%$ of reconstructed spectra could not be distinguished from original spectra as estimated using the RNL model of bird colour vision. 
Methods S2 Phylogenetic relationships among the 102 Spanish plant species.

We first established relationships between families by discarding all but the 28 families included in our study from a published phylogeny of the angiosperms (Davies et al., 2004). Relationships between genera were obtained from the literature when available. The resulting cladogram was then converted into an ultrametric tree by aging interior nodes. Age of nodes located between the root and the families were retrieved from the Davies et al.'s tree. At and down to family level, ages were assigned from Wilkström et al. (2001). For families represented by more than one genus, the age of the family node corresponds to the family age given in this article. For families represented by a single genus, we assigned age as half the family age. Although arbitrary, this procedure avoids overestimating the divergence time of species for those families. For the remaining nodes, we reduced variance between branch lengths by using the BLADJ algorithm which evenly spaces nodes of unknown ages. 